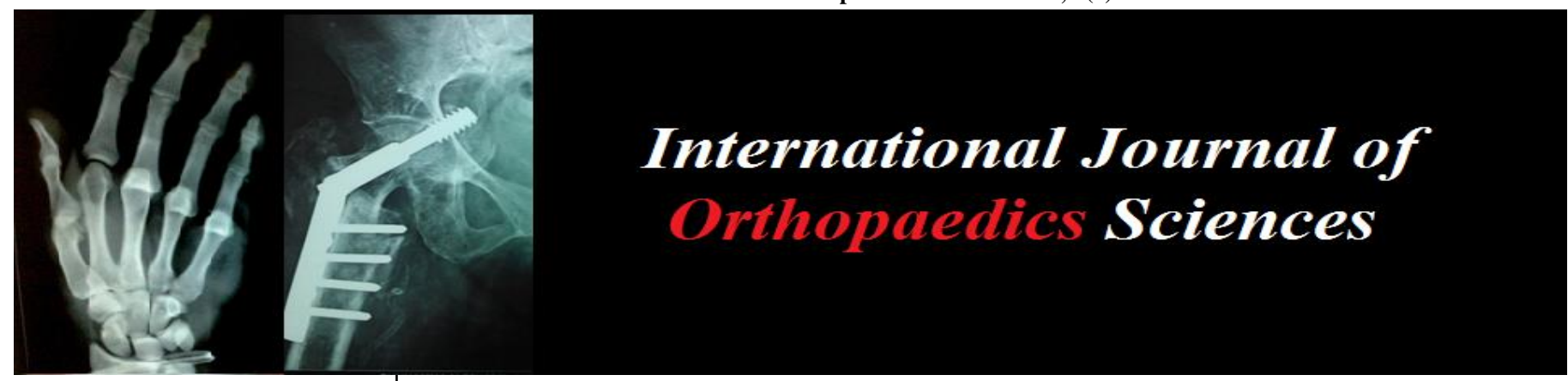

E-ISSN: 2395-1958

P-ISSN: 2706-6630

IJOS 2020; 6(2): 148-154

(C) 2020 IJOS

www.orthopaper.com

Received: 01-01-2020

Accepted: 05-02-2020

Dr. Ullas T Shetty

Senior Resident, Department of Orthopaedics, Mysore Medical College and Research Institute, Mysore, Karnataka, India

Dr. Srikant Kulkarni

Senior Resident Department of Orthopaedics, Shri B. M. Patil

Medical College Hospital and RC

Vijayapura, Karnataka, India

Dr. Siddhant Gandhi

Junior Resident, Department of Orthopaedics, Shri B. M. Patil

Medical College Hospital and RC Vijayapura, Karnataka, India
Corresponding Author: Dr. Ullas T Shetty Senior Resident, Department of Orthopaedics, Mysore Medical College and Research Institute, Mysore, Karnataka, India

\section{A clinical study of fractures of patella treated with modified tension band wiring}

\author{
Dr. Ullas T Shetty, Dr. Srikant Kulkarni and Dr. Siddhant Gandhi
}

DOI: https://doi.org/10.22271/ortho.2020.v6.i2c.2029

\section{Abstract}

Background \& Objectives: In a country like India where the social habits and needs, require full range of knee flexion, the patella plays an important role. The most significant effect of patella fracture are loss of continuity of extensor mechanism of knee and potential incongruity of patello-femoral articulation. So it is necessary to preserve the patella and extensor apparatus.

Hence the main objectives of this study are: To study the functional outcome by early mobilization, to study the complications of tension band wiring, to clinically evaluate the tension band wiring technique for fracture patella, to study the mode of injury for fracture patella.

Methods: The present study consists of 30 selected cases of fractured patella treated by modified tension band wiring at Shri B M Patil Medical College Hospital and Research Centre, Vijayapur from December 2014 to March 2016.

Results: In the present study $21(70 \%)$ had excellent results, 7 (23.33\%) had good results and 2(6.66\%) had poor result.

Interpretation and Conclusion: Early mobilization of the knee restores quadriceps power and range of Kneemotion within a short period. Excellent range of movement was achieved in $70 \%$ of cases, which is comparable to previous literature.

Keywords: Patella, Kirschner wire, tension band

\section{Introduction}

The patello-femoral joint is the heaviest-loaded joint in the body. Anycompromise of the joint surface is likely to lead to degenerative jointdisease. It is, therefore, highly desirable, in patellar fractures to strive foranatomical reduction of the joint surface and stable fixation. In addition, atreatment goal is restoration of function of the knee extensor mechanism.

Fractures of the patella are common and constitute almost $1 \%$ of all skeletalinjuries. Several methods of internal fixation of fractured patella have been advocated. This study is directed towards the clinical evaluation of the modified tension and wiring technique for the fractured patella.

\section{Objectives of the study}

To study the functional outcome of modified tension band wiring in fracturepatella and its associated complications.

\section{Materials and Methods}

The present study consists of 30 selected cases of fractured patella treated by modified tension band wiring at the Shri B M Patil Medical College Hospital and Research Centre, Vijayapur. from December 2014 to March 2016.

Standard preoperative protocol was followed

Treatment: After the X-rays the limb was immobilized by an above knee POP posterior slab. Operations were done at a later date. If abrasions were present in the skin they were cleaned, dressed and antibiotics given. Patients were prepared for surgery during this period. On the day before the surgery the part was prepared and antibiotics started. Patients were taught static quadriceps drill and straight leg raising exercises. 


\section{Technique of operation}

Operative Procedure The operation was performed under spinal anaesthesia. Tourniquet was applied to the upper part of the thigh and the part was painted with iodine and spirit and draped. A vertical lazy 'S' incision was put over the anterior aspect of the knee. The skin and fascia were retracted to expose the fracture site. The knee was flexed to 20 and positioned on a roll. The fracture surface was cleaned of all bloodclots. The extent of retinacular tears was explored and the joint inspected forany damage to the femur. The joint was then thoroughly lavaged. About $5 \mathrm{~mm}$ from the anterior surface of the patella, one hole is drilled with a $2 \mathrm{~mm}$ drill bit, from the fracture surface. A $1.5 \mathrm{~mm} \mathrm{~K}$ wire is inserted in the firsthole and is used as a guide to drill the second hole parallel to the first. To easedrilling the proximal fragment is held with reduction clamps and the fragmenttipped so that the fracture surface faces the surgeon.

Now the fracture is reduced with reduction clamps. The accuracy of the reduction is checked by inspecting and palpating the anterior and posterior surface in case of retinacular tear. Now the $\mathrm{K}$ wires are removed and two holes are drilled in to the distal fragment from the proximal fragment. The drill bit is removed and replaced with $1.5 \mathrm{~mm}$ $\mathrm{K}$ wires which are hooked at the tip. A 20 gauge wire is passed around the $\mathrm{K}$ wire in a figure of 8 pattern so that the knot comes to lie next to the proximal end of the lateral $\mathrm{K}$ wire. This facilitates future metal removal. Thewire is then tightened with the A.O tightener. After tightening the wire the tighteneris tipped $90^{\circ}$ and cut about $1 \mathrm{~cm}$ long and the cut end burried in the soft tissues.

The $\mathrm{K}$ wires are adjusted so that the curved ends face backwards, pulled down and hammered into bone. The distal portions are cut off about $1 \mathrm{~cm}$ from where they exit from bone. The joint capsule and quadriceps retinaculae aremeticulously repaired and the fascia repaired with plain sutures. The skin is closed with interrupted mattress sutures and a compression bandage given.

\section{Operative Procedure}

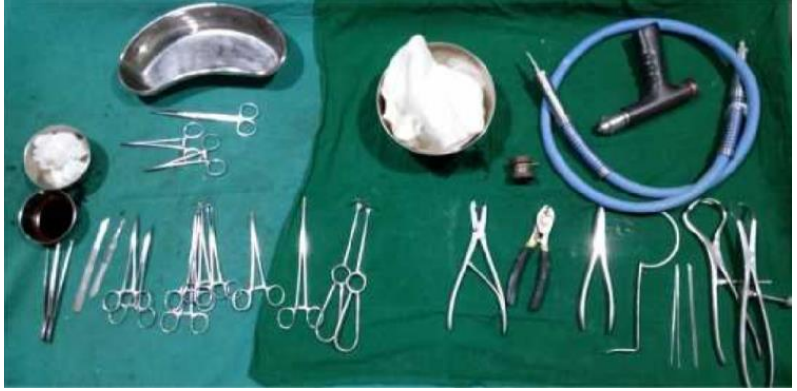

Fig 1: Instruments

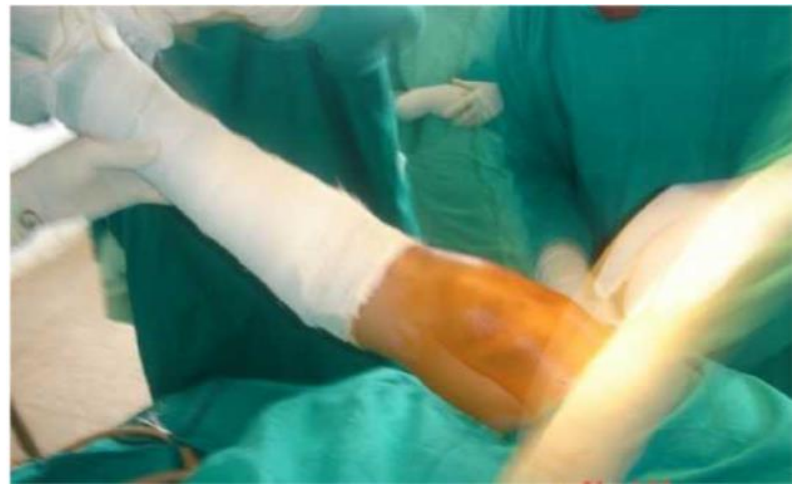

Fig 2: Painting and draping

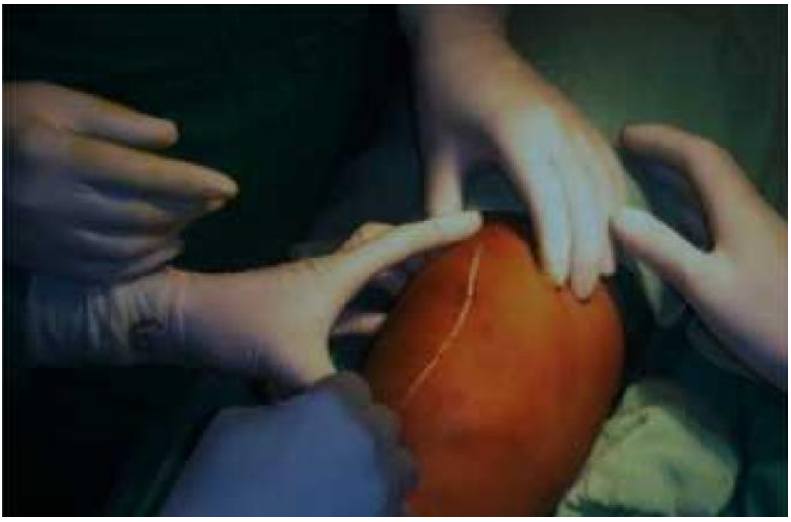

Fig 3: Skin incision

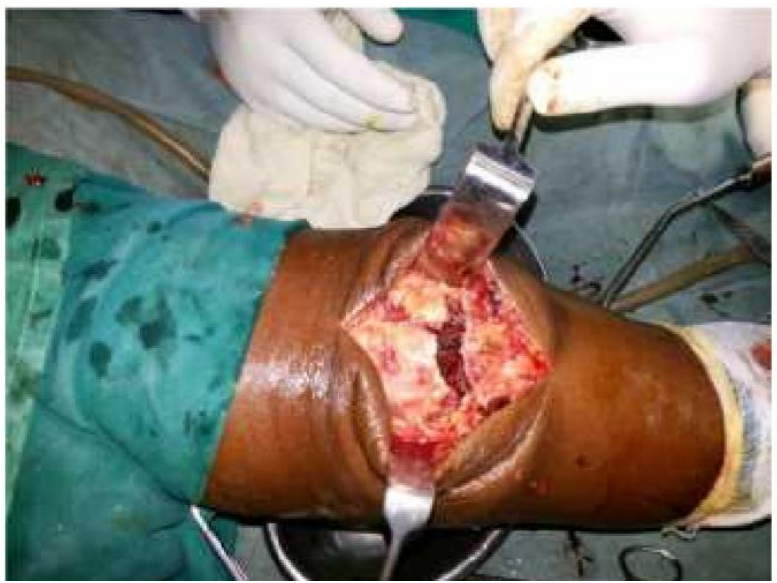

Fig 4: Exposure of fracture fragments

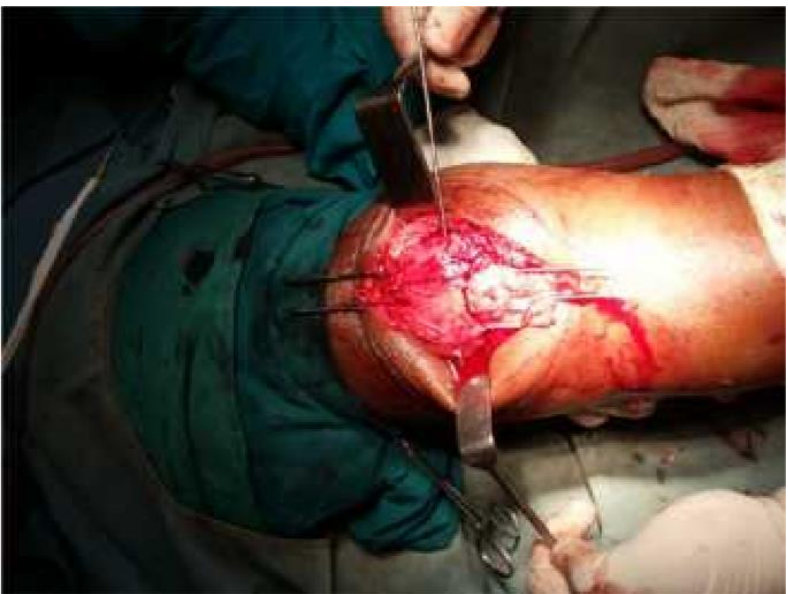

Fig 5: Fracture reduction and k-wire fixation

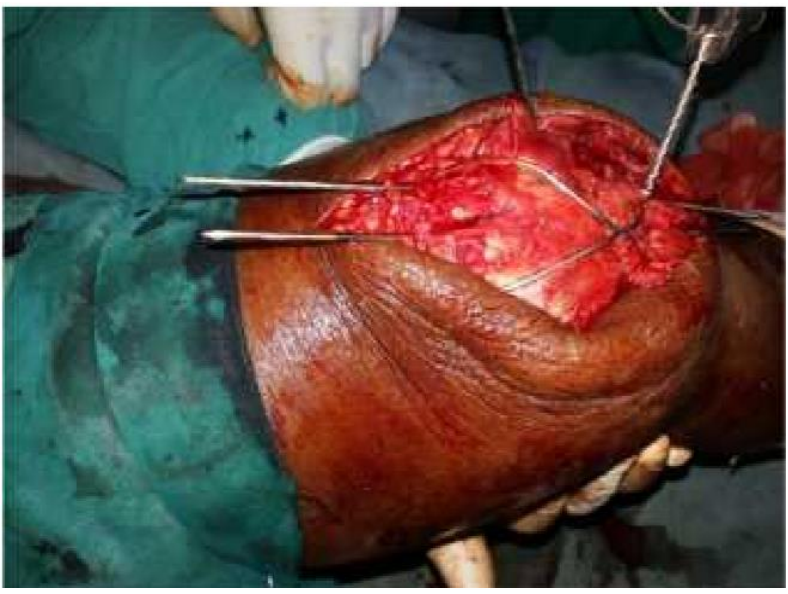

Fig 6: Cerclage wiring 


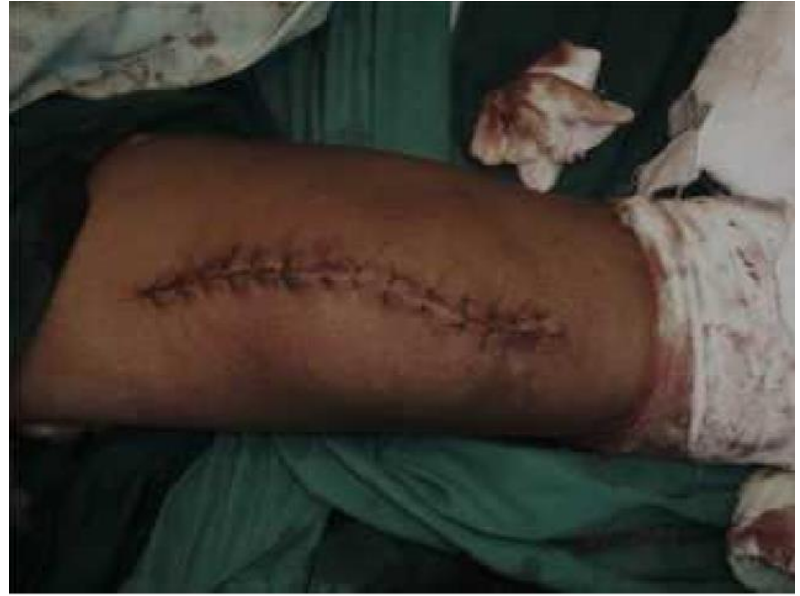

Fig 7: Skin closure

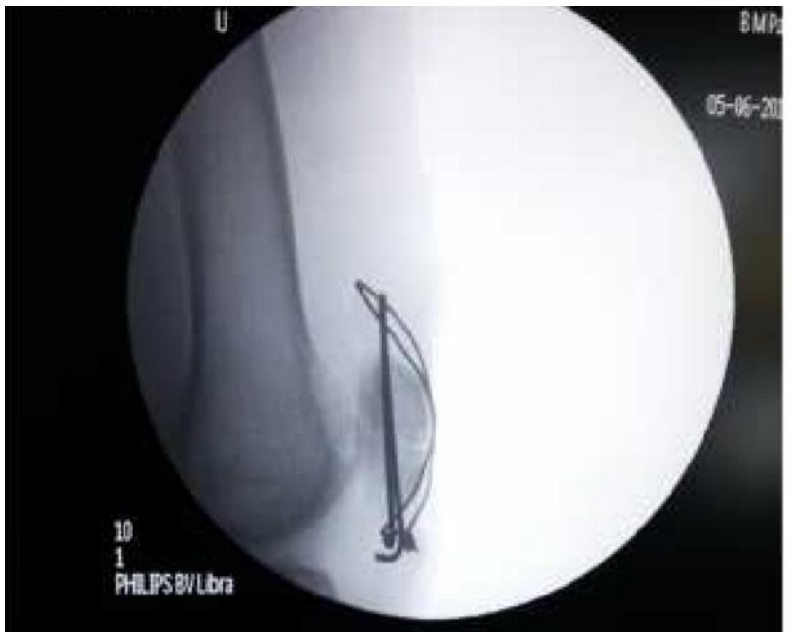

Fig 8: Intra operative image

\section{Post-operative management}

The patient is adviced to do quadriceps exercises from the first postoperative day onwards and is allowed full weight bearing from the 3rd day afterremoval of the compression bandage. Later knee flexion was started with thequadriceps board, and continued with the continuous passive motion machine. The patients were then taught dynamic quadriceps exercises which they could dothemselves at home, advised to do them regularly and discharged on the 14th day.

\section{Follow up}

The patients on discharge were advised to report for follow up after 1 monthin the first instance and then after every 2 months for 6 months.

During each follow up patients were questioned about subjective complaints like pain, difficulty in walking, squatting, climbing and steppingdown stairs and inability to perform normal work.

\section{For objective assessments patients were examined for}

1. Extension lag

2. Range of knee motion

3. Circumference of thigh

4. Efficiency of the quadriceps

5. X-ray examination of knee joint.

\section{Observation and results}

Since the advent of surgical treatment of the fracture patella, opinion has changed from one advocating removal of the patella to on preserving either part orpreferably whole of the patella. If the fragments can be realigned and fixed in such away that once it heals, it is in no way different from its prefractured status, it would be the ideal treatment. In this series 30 cases of fractured patella were treated inpatients between the age group of $20-50$ years by the modified tension band wiring technique, special attention was given to mobilize the knee early as it helps to regain the quadriceps power.

Table 1: Age incidence

\begin{tabular}{|c|c|c|}
\hline Age in years & Number of cases & Percentage \\
\hline $20-30$ & 6 & 20 \\
\hline $31-40$ & 15 & 50 \\
\hline $41-50$ & 9 & 30 \\
\hline
\end{tabular}

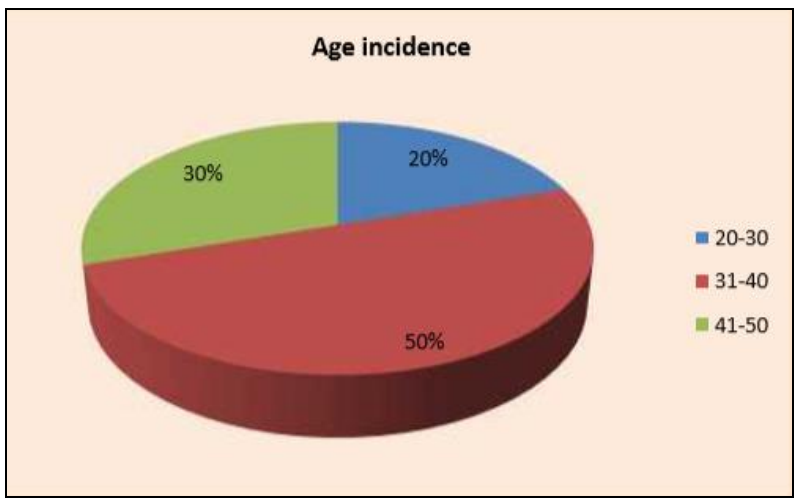

The mean age was 40 years and maximum incidence was between 31 to 40 years.

Table 2: Sex incidence

\begin{tabular}{|c|c|c|}
\hline Sex & Number of cases & Percentage \\
\hline Male & 18 & 60 \\
\hline Female & 12 & 40 \\
\hline
\end{tabular}

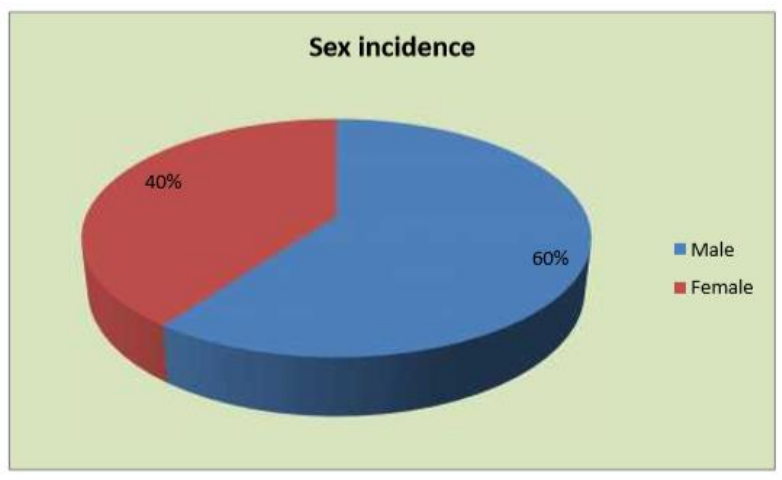

In this series male sex predisposition was observed.

Table 3: Type of Fracture

\begin{tabular}{|l|c|c|}
\hline \multicolumn{1}{|c|}{ Type of fracture } & Number of cases & Percentage \\
\hline Transverse fracture & 24 & 80 \\
\hline Communited fracture & 6 & 20 \\
\hline
\end{tabular}




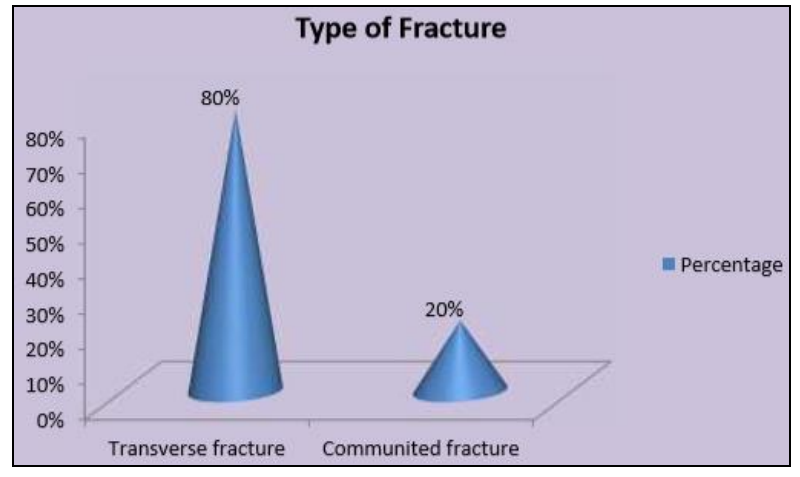

Follow Up

Patients were followed up one month after discharge and then every 2 months. In this series the follow up period ranged from 2 months to 9 months.

The mean time was 5 months. During each follow-up the patients were questioned about the following subjective complaints and examined for the followings deficiencies.

Table 4: Subjective Complaints following Modified Tension Band Wiring

\begin{tabular}{|l|c|c|}
\hline \multicolumn{1}{|c|}{ Complaints } & Number of Cases & Percentage \\
\hline Pain & 9 & 30 \\
\hline Mild Difficulty In Squatting & 9 & 30 \\
\hline Difficulty In Climbing Stairs & - & - \\
\hline $\begin{array}{l}\text { Difficulty In Stepping Down } \\
\text { Stairs }\end{array}$ & - & - \\
\hline $\begin{array}{l}\text { Sense Of Weakness Or Giving } \\
\text { Way Of Knee }\end{array}$ & - & - \\
\hline
\end{tabular}

\section{Pain}

All the cases had pain during the first 2 weeks. In the present study 21

cases gave excellent results were in they complained of no pain after 2 months. 7

cases considered to be good cases with mild pain at the end of 2nd month. 2

cases complained of persistence of pain even after the end of 2nd month is graded as

poor.

Table 5: Objective deficiency after modified tension band wiring

\begin{tabular}{|l|c|c|}
\hline \multicolumn{1}{|c|}{ Deficiency } & Number of cases & Percentage \\
\hline Limitation of flexion & 9 & 30 \\
\hline Quadriceps wasting of 1cm & 9 & 30 \\
\hline Quadriceps power of grade-4 & 9 & 30 \\
\hline Extension lag & - & - \\
\hline
\end{tabular}

\section{Movements}

In this series 8 cases had limitation of flexion of only terminal $20^{\circ}$ offlexion and one case had only $40^{\circ}$ of flexion and so 9 cases had limitation of knee flexion. All the other 21 cases had complete range of knee movement.

Wasting of Thigh:

In this series 9 cases had one centimeter wasting. Early and effective physiotherapy is essential in obtaining an excellent result.

\section{Power of the Quadriceps}

Quadriceps strength was graded 0-5 from no muscle activity to full strength. It was assessed by comparing with the normal side. In this series only 9cases had grade- 4 strength. All the other cases had grade-5. Patient cooperation and physiotherapy are very important for the recovery of muscle power and function of knee joint.

\section{Results}

In this 18 cases were male and 12 cases were female, 18 cases were having indirect injury and 12 were having direct injury. 21 cases graded as excellent, 7cases graded as good and 2 cases as poor.

\section{Criteria to grade the cases mentioned below}

1. Excellent: This knee was functionally normal. The patient has no subjective complaints like pain, difficulty in squatting and climbing steps and objective deficiencies like quadriceps wasting and limitation of flexion and extension and normal quadriceps power.

2. Good: There was occasional pain. Patient can squat and climb steps with some difficulty. Limitation of flexion less than $20^{\circ}$, quadriceps wasting less than $1 \mathrm{~cm}$, and reduction of quadriceps power from grade- 5 to grade- 4 .

3. Poor: Cases which failed to attain the above standards.

Table 6: Results in this study

\begin{tabular}{|l|c|c|}
\hline Results & Number of cases & Percentage \\
\hline Excellent & 21 & 70 \\
\hline Good & 7 & 23.33 \\
\hline Poor & 2 & 6.66 \\
\hline
\end{tabular}

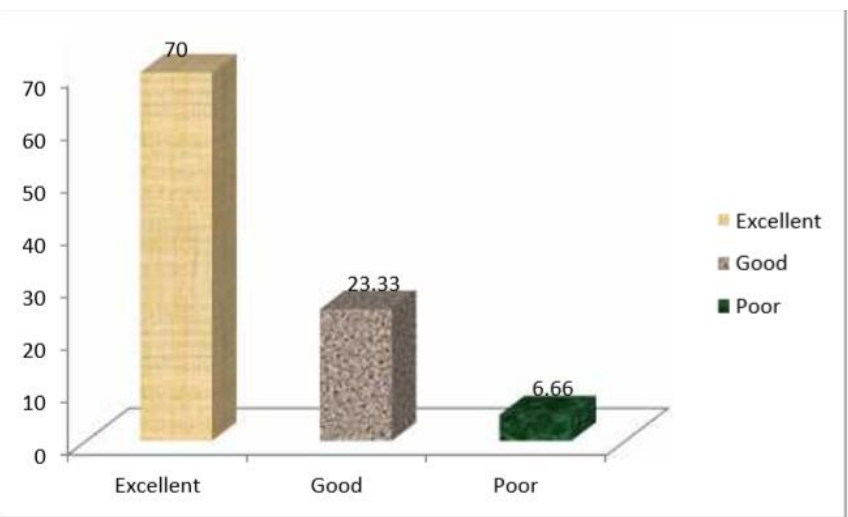




\section{Case illustration}

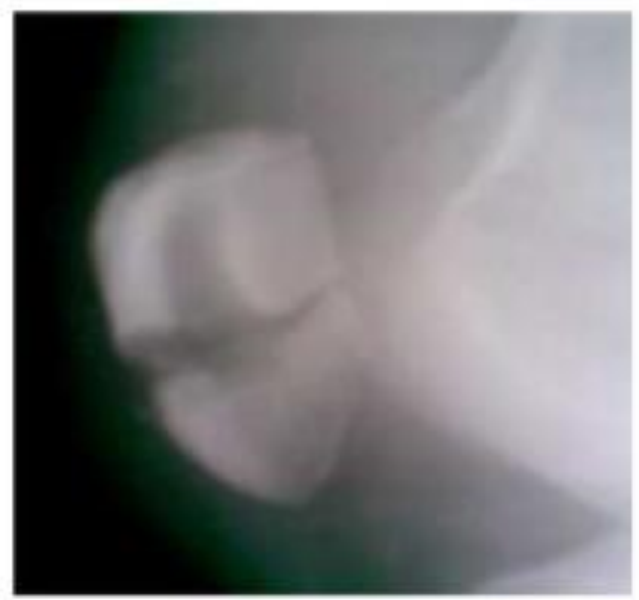

PRE-OPERATIVE

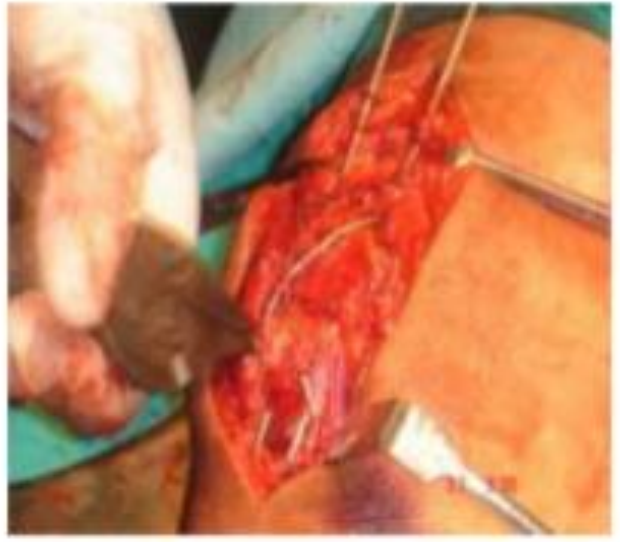

INTRA OPERATIVE

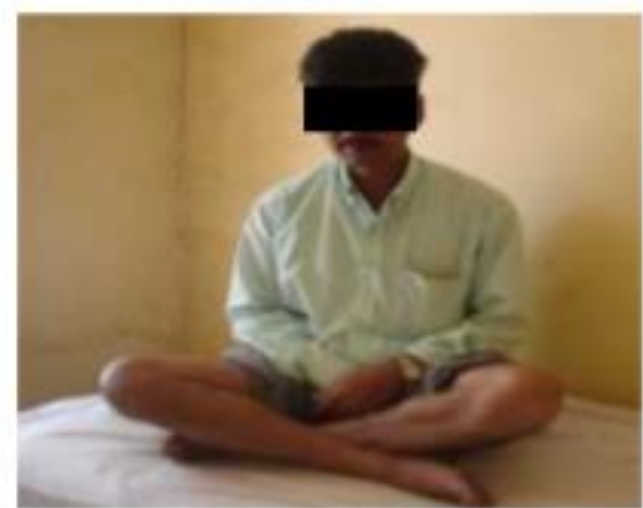

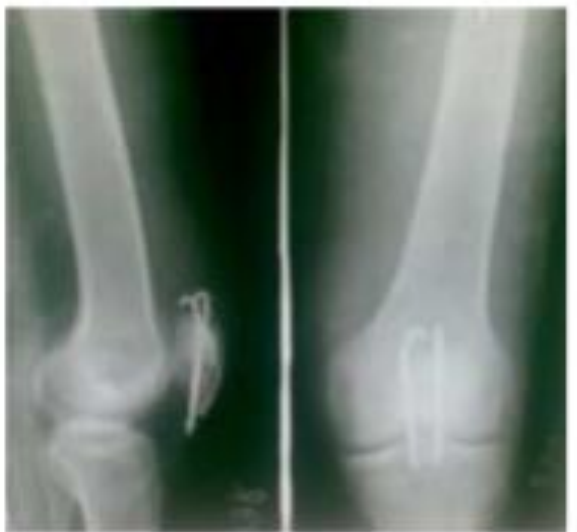

IMMEDIATE POST-OPERATIVE

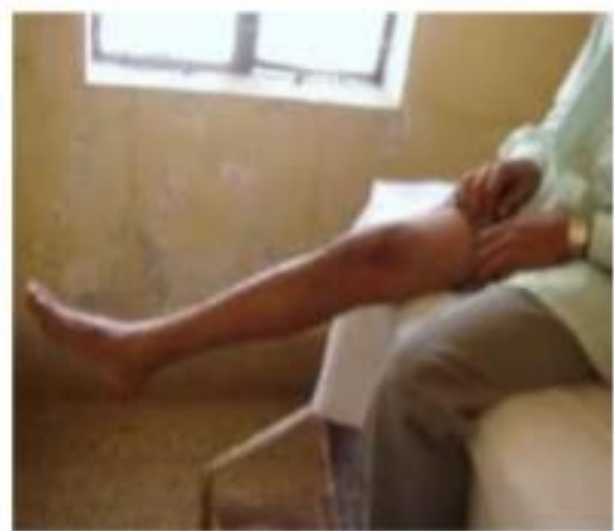

\section{FINAL FOLLOW-UP}

\section{Discussion}

Since the advent of surgical treatment of the fractured patella, opinion has changed from one advocating removal of the patella to one preserving either part or preferably whole of the patella. If the fragments can be realigned and fixedin such a way that once it heals, it is in no way different from its prefractured status, it would be the ideal treatment.

In this series 30 cases of fractured patella were treated by the modified tension band wiring technique. Special attention was given to mobilize the knee early as it helps to regain the quadriceps power. The findings, the end results and various other data will be analysed and compared in the following discussion.

Fracture patella can occur at any age. But the frequency in children and adolescents under 20 years of age is low. In this series the range of age was taken between 20 to 50 years. The mean age was 45 years and maximum incidence was between 31 to 40 years. In Bostrom (1972) series, the mean age was 48 years ranging between 16 to 89 years. 28 S.K. Basu Ray and M.S. Ghosh intheir series of 24 cases found the range of age between 18 years and 62 years In R.E. Peoples et al. (1977) series, the average age was more than 20 years. 
Table 7: Different of male and female study

\begin{tabular}{|c|c|c|}
\hline Study & Male & Female \\
\hline S.K.Basu Roy and M.S. Ghosh & $71 \%$ & $29 \%$ \\
\hline Jonathan Wilkinson & $68 \%$ & $32 \%$ \\
\hline Present study & $60 \%$ & $40 \%$ \\
\hline
\end{tabular}

In general it can be said that the patella fracture commonly occur in males because of an active and vigorous life style. In present series also male sex predisposition was observed.

\section{Type of Fracture}

Two types of fractures were found to have occurred in the present series $20 \%$ were comminuted and $80 \%$ were transverse fracture.

Subjective Complaints following Modified Tension Band Wiring:

In the present study subjective complaints like pain was observed in9(30\%) patients and difficulty in squatting was observed in $9(30 \%)$ patients.

Objective deficiency after Modified tension band wiring:

In the present study $9(30 \%)$ patients had flexion limitation, quadriceps wasting was observed in $9(30 \%)$ patients a quadriceps power of grade IV was observed in $9(30 \%)$ patients. There was no extension lag in any of the cases.

Table 8: Result comparison

\begin{tabular}{|l|r|r|r|r|r|r|r|}
\hline \multicolumn{1}{|c|}{ Study } & $\begin{array}{c}\text { No of } \\
\text { cases }\end{array}$ & $\begin{array}{l}\text { Excellen } \\
\text { t }\end{array}$ & Percent & Good & Percent & Poor & Percent \\
\hline Marya, Bhan, Dave $^{14}$ & 30 & 24 & 80 & 4 & 13.33 & 2 & 6.66 \\
\hline Levack,Flannagan Hobbs $^{30}$ & 14 & 7 & 50 & 5 & 35.71 & 2 & 14.28 \\
\hline Dudani, Sancheti $^{12}$ & 15 & 11 & 73.33 & 4 & 26.66 & 0 & 0 \\
\hline Present study & 30 & 21 & 70 & 7 & 23.33 & 2 & 6.66 \\
\hline
\end{tabular}

In the present study $21(70 \%)$ had excellent result, $7(23.33 \%)$ had good results and 2(6.66\%) had poor results.

Dudani, Sancheti12 in their study also found similar results $11(73.33 \%)$ had excellent result and $4(26.66 \%)$ had good result.

Marya, Bhan, Dave14 found 24(80\%) had excellent result, $4(13.33 \%)$ had good result and $2(6.66 \%)$ had poor result.

But Levack, Flannagan, Hobbs30 found $7(50 \%)$ had excellent result,5(35.71\%) had good result and 2(14.28\%) had poor result.

\section{Conclusion}

Fractures of the patella are common though rare below the age of 20years. Fall in the same plane is the most common cause of fractures of the patella.

Vertical incision is more helpful to mobilize the patient early. Early mobilization of the knee restores quadriceps power and range of knee motion within a short period.

Excellent range of movement was achieved in $70 \%$ of cases.

Early and continuous physiotherapy following the modified tension band wiring technique is of paramount importance in determining the end results.

Modified tension band wiring is therefore the choice of treatment for the fracture patella.

\section{References}

1. Matthew I. Rudloff Campbell's operative orthopaedics. Chapter 54. $12^{\text {th }}$ edition, Edt. S. Terry Canale, James H. Beaty, Elsevier Mosby. 2013; 3:2681-2688.
2. Haxton HA. The functions of the patella and the effects of its excision. Surg Gynaec Obst. 1945; 80:389.

3. Kaufer H. Mechanical function of the patella. JBJS. 1971; 53(A): 1551.

4. Cameron HC. Transverse fracture of the patella. Glasgow Med J. 1878; 10:289-294.

5. Heineck AP. The modern operative treatment of fracture of the patella: I. Based on the study of other pathological states of this bone. II. An analytical review of over 1,100 cases treated during the last ten years, by open operative method. Surg Gynecol Obstet. 1909; 9:177-248pp.

6. Thompson JEM. Fracture of the patella treated by removal of the loose fragments and plastic repair of the tendon. Surg Gynecol Obstet. 1942; 74:860-866.

7. Cohn BNE. Total and Partial patellectomy. Surg Gynecol Obstet. 1944; 79:526-536.

8. Douglas CD, Netto. Fractures of the Patella. PGMJ. 1963; 39:83.

9. Smilie IS. Injuries of the knee joint. 4th edition, Churchill Livingstone, London, 1978.

10. Muller ME, Aiigower M, Willinegger $\mathrm{H}$. Technique recommended by the AO group. In: Manual of internal fixation. New York: Sphringer-Verlag, 1979, 249-250.

11. Weber MJ, Janecki CJ, McLeod P et al. Efficacy of various forms offixation of transverse fractures of the patella. JBJS, Am, March 1980, 62(2).

12. Dudani B, Sancheti KM. Management of fracture patella by tension bandwiring. Ind. J of Ortho. 1981; 15-1:43-48.

13. Ma YZ, Zhang YF, Qu KF et al. Treatment of fracture of the patella, with percutaneous suture. Clin Ortho. 1984; 191:235-241.

14. Marya SK, Bhan S, Dave PK. Comparative study of knee function after patellectomy and osteosynthesis with a tension band wire following patellar fractures. IntSurg, 1987, 72(4).

15. Benjamin J, Bried J, Dohmm et al. Biomechanical evaluation of variousforms of fixation of transverse patellar fracture. J Ortho Trauma. 1987; 1:219.

16. Curtis MJ. Internal fixation for fractures of the patella. A comparison of two methods. JBJS Br, 1990, 72 (2).

17. Carpenter JE, Kasman RA, Patel N et al. Biomechanical evaluation of current patella fracture fixation techniques. J Orthop Trauma. 1997; 11:351356.

18. Gray's Anatomy, 40th edition, Churchill Livingstone. 2008; 82:1393-1410.

19. Cunningham's manual of practical anatomy, 15th edition, ELBS, Oxford University Press. 1984; 1:215-221.

20. Scapinelli R. Blood supply of the human patella. JBJS. 1967; 49(B):563570.

21. Sven Bjorkstorm, Ian F. Goldie. A study of the arterial supply of the patella in the normal state, in chondromalacia patellae and in Osteoarthritis. Acta. Orthop. Scand. 1980; 51:63-70.

22. Fredrick J Liee. Quadriceps mechanism of the knee JBJS, 1966; 48(6):51-54

23. Grooves EW. Hey. A note on the extension apparatus of the knee joint. Br. J Surg. 1937; 24:747-748.

24. Asheesh Bedi, Madhav A Karunakar. Rockwood and Green's Fractures in adults, Charles A. Rockwood, Robert W. Bucholz (Edt), Chapter 52, $7^{\text {th }}$ edition, Philadelphia, Lippincott Williams \& Wilkins. 2010; 2:17521779.

25. Kroner M. Ein Fait von Flachen fractur und Luxation der patella Dtsch Med Wochenschr. 1905; 31:996.

26. Desai NN. A study of different types of treatment in 
fractures of the patella. Ind J Surg. 1972; 34:54.

27. Brooke R. Treatment of fracture patella by excision. A study of morphology of function. Br. J Surg. 1936-37; 24:733.

28. Bostrom A. Fractures of the patella: A study of 422 patellar fractures. Acta ortho Scand. 1972; 143:1-80.

29. Logan Clark. Conservative treatment for Comminuted fracture of the patella. JBJS. 1969; 51(B):776.

30. Levack B, Flannagan JP, Hobbs S. Results of surgical treatment of patellar fractures. JBJS. 1985; 67-B:416419. 